\title{
Interpretation of Elementary School Mathematics Material in Motion Comic
}

\author{
Karlimah $^{1}$, Ghullam Hamdu ${ }^{2}$, Ade Yulianto ${ }^{3}$ \\ \{karlimah@upi.edu¹, ghullamh2012@upi.edu², adeyulianto@upi.edu³ $\}$ \\ 1,2,3Primary Teacher Education, UPI Tasikmalaya Campus
}

\begin{abstract}
The era of industrial revolution 4.0 is an inevitability for people living in the 21 st century. Many advanced devices are used in interacting in various areas of activity, including education. In mathematics learning can also use sophisticated devices and various platforms or applications according to the development of science and technology. Similarly, students who started their lives in the 21 st century, many are familiar with the development of science and technology and use it in daily life. Therefore, it is appropriate if mathematics learning adapts to life in the era of industrial revolution 4.0. to overcome the dislike of mathematics and the difficulty in learning mathematics. Making mathematics motion comic is an effort to attract interest and facilitate learning mathematics. Motion comic is a moving comic, in the form of digital comics that are interesting and light to be read / watched by elementary school-age learners. Packing mathematical material in motion comic is to develop the comic and create the animation. The process of making mathematics motion comic consists of three stages, namely: prep roduction, production and post production. Principles of developing comics, paying attention to ideas or goals, forms, idioms, structures, craft, surfaces. To obtain motion comic continued by making the animation. Mathematical materials in comics are poured in ideas or objectives according to the curriculum. Forms, idioms, and structures are created according to comics and mathematical materials. Craft and surface that polishes math comics into books that are light to read, interesting, and easy for students to learn math. Along with making mathematical comics think about animation based on three main plots of the animation process, namely: designing, executing, analyzing the results of animation. The success of delivering mathematics in motion comic is measured by the suitability of the material with the curriculum and objectives, the delivery of materials in accordance with visual indicators, the presentation of motion comic that is preferred and can understand mathematics.
\end{abstract}

Keywords: elementary school math, motion comic, interpretation

\section{Introduction}

The industrial revolution 4.0 is an era of life and the development of human knowledge/ experience who lives with machines that can help cope with work and life's needs. The era of the industrial revolution 4.0 has influenced human life, especially the alpha generation. Generations who from the beginning of their growth and development were served by the concept of automation that is widely used in everyday life, so they are accustomed to dealing with the use of a lot of time, energy and costs in dealing with an activity / job. Like the experience of doing daily work at home, it is usual to be assisted by machines. The alpha generation is the generation most familiar with the internet of all time, this is the background for the need to use technological developments for the advancement of education in Indonesia [1]. In line with this, Riansi\& Saputra conveyed the era of the industrial revolution 4.0, 
Ssynonymous with technological developments that can be used in the implementation of learning [2].

The experience of the alpha generation, which is familiar with digital technology from an early age, makes teachers not the only source of learning. Technology is one that allows it to be used as a learning facility [3]. Thus, teachers must be able to use technology as another learning facility for students. There are many choices of learning resources that can be used in the era of the industrial revolution 4.0, including learning resources that are packaged using digital media [4]. In addition, the choice of learning resources can touch the psychology of children or students in elementary schools [5].

Students in elementary schools are still equipped with many fundamental, holistic experiences from each subject [6]. For this reason, learning resources must be able to provide knowledge and skills, especially getting used to attitudes. Thus, basic skills as a tool to gain knowledge and knowledge, namely reading, are needed. Several facilities that can be used in fostering the needs of students for reading and learning are pursued in the form of comic book media. Comic books are books that are attractive to students in elementary schools, because they are filled with pictures to make it easier to absorb information.

Educative comics have also been widely distributed in the community, but comic books about mathematics are still very minimal. Several facilities that can be used in fostering the needs of students for reading and learning are pursued in the form of comic book media. Comic books are books that are attractive to students in elementary schools, because they are filled with pictures to make it easier to absorb information. Educative comics have also been widely distributed in the community, but comic books about mathematics are still very minimal. Several facilities that can be used in fostering the needs of students for reading and learning are pursued in the form of comic book media. Comic books are interesting books for students in elementary school, because they are filled with pictures to make it easier to absorb information. Educative comics have also been widely distributed in the community, but comic books about mathematics are still very minimal.

However, with the industrial revolution 4.0, comic books need to be adapted to the development of science and technology. The availability of educational comic books so far needs to be considered to be developed according to the development of science and technology. Moreover, comics that are packaged in digital form provide a special attraction for readers. In the current digital revolution era, comics are not only presented in print, but can be presented in digital form.

The term digital comic is better known as motion comics. Motion comics are digital forms of books or pictorial reading materials with a specific theme. Motion comics have elements that elementary school children like, namely funny pictures and interesting stories. Rohani said that "a comic is a cartoon that reveals a character and shows a story in a close sequence, connected with pictures and designed to provide entertainment to the reader" [7]. It is clear that comics are preferred by students than ordinary textbooks. While regarding cartoons, Hermawan, et al. explained that "... cartoons can provide motivation and attract students' attention and foster interest in learning" [8].

Smith examines the influence of technological developments on the emergence of motion comics [9]. The new appearance of comics in digital form and equipped with various advantages is considered a medium that is relevant to technological developments and the current conditions of education. Along with the development of technology, there is a development of art in images in the form of animation. Animation is also a collection of images that make up a story. McCloud explains that animation is a collection of images so that it looks moving and is separated by time or frame by frame [10]. 
Motion comicswhich is developed contains math learning content without eliminating comic elements that are liked by children by paying attention to the principles of motion comic development. Motion comics will be the right educational media for elementary school students to use, in addition to helping convey abstract mathematical concepts to other forms that are easy to understand, this media can make students feel that they are not only carrying out their obligations as students but also as a means of entertainment for them. students.

\section{Method}

This research uses qualitative methods, which intend to understand the phenomenon of what research subjects experience holistically in a natural context and by utilizing various natural methods [11]. In this study, the researcher was used as a key instrument "the researcher is the key instrument" [12]. Basically, this research is the initial stage of the activityresearch and development (R\&D) with a model that refers to the opinion of Borg and Gall [13], at this stage it is more specific to use Descriptive qualitative method is used because the researcher wants to describe the principle of motion comic development in mathematics learning in elementary schools. The stages of this research are based on the explanation of Creswell [14], namely:

2.1 Identification of problems; The researcher conducted a literature study on problems relating to technology users and the development of mathematics learning media especially for elementary school students.

2.2 Literature Review; The researcher conducts a literature review by examining concepts and theories relevant to the research to be carried out.

2.3 Specifying Research Objectives; As a follow-up to identifying the problem to be researched, the writer specifies the objectives to be achieved in this study, namely the researcher will describe the principles of developing motion comics in the context of learning mathematics in elementary schools.

2.4 Data collection; data collection is done by collecting the results of research that has been done before.

2.5 Data Analysis and Interpretation; Researchers categorize the results of previous studies and describe them.

2.6 Reports and Evaluation of Research Results; Furthermore, the writing of the research results is presented in a descriptive way, tables and diagrams.

\section{Discussion}

In the long history of comics there has been no definition of a comic which is only a picture of a story or event. Until finally there was a phrase McCloud namely 'sequential art', which became the basis for the meaning of a comic [10]. He argues that comics are a collection of images that are juxtaposed sequentially to create a storyline. McCloud illustrates the meaning of the comic from ancient Egyptian images which contain a story. Eisner also states that comics are a way of telling stories that have a unique writing style [15]. This uniqueness is a writing style that is not only text, but the reader is also given additional imagery by means of a collection of images. 
Along with the development of technology, there is a development of art in images in the form of animation. Animation is also a collection of images that make up a story. McCloud explains that animation is a collection of images so that it looks moving and is separated by time or frame by frame [10]. Meanwhile, the difference in comics is a collection of images separated by lines or better known as panels. However, in 2008, Dave Gibbons and Alan Moore from Warner Bros. created a work entitled "Watchmen" which brings panels and comic features but can be watched like an animation. This work is what they call "Motion Comic". Smith stated that the presence of motion comics brings new experiences and opportunities in an industry. With a blend of comic and animation styles [9].

In developing comics, of course, clear indicators or principles are needed to guide the development process. McCloud generalizes six principles in making image art, especially comic development, namely ideas, forms, idioms, structure, surface and craft [10]. The principle of developing this comic can be interpreted in the development of learning materials through motion comics, more specifically in interpreting mathematics material in elementary schools. As for the explanation of the principles of comic development in mathematics learning in elementary schools, namely:

3.1. Ideas; The development idea is basically an idea that will be addressed in the comic development process. In this case, the idea is based on the desire to design mathematics learning activities to be more attractive, easier to understand and to make comics in mathematics learning as an alternative educational media. For example, came up with the idea of conveying fraction material $\left(\frac{a}{b}\right)$ in a motion comic that must apply the concept of fractions correctly at the same time being interesting and easy to understand. Think about how fractions are written which should be written $\frac{\boldsymbol{a}}{\boldsymbol{b}}$, where $\boldsymbol{a}$ is also $\boldsymbol{b}$ which is an integer, and $\mathbf{b}$ cannot be $\operatorname{zero}(\mathbf{b} \neq \mathbf{0})$. Besides, how to introduce that $\boldsymbol{a}$ is called the numerator and $\boldsymbol{b}$ is called the denominator. In principle, it is also important to think about how to introduce fractions which are symbols of the reality of parts of the whole.

3.2. Forms; The development of forms in comics will serve as an attention grabber for children, the forms developed are mathematical material that is given additional visuals typical of comics because in general children like pictures so that the messages to be conveyed in comics will be more effective and easily accepted by children [16]. This the idea conveys the concept of fraction numbers $\frac{\boldsymbol{a}}{\boldsymbol{b}}$ continued on the selection and determination of aspects of images and animation. There are eight aspects of images and animation, namely: 1) visual, 2) appropriate color selection, 3) representative image form depiction, 4) typography, 5) layout, 6) visual elements of motion (animation), 7) communicative, 8) unity. These eight aspects organize the conceptual presentation of fraction numbers $\frac{\boldsymbol{a}}{\boldsymbol{b}}$, where $\boldsymbol{a}$ and $\boldsymbol{b}$ are integers, and $\boldsymbol{b}$ cannot be $\boldsymbol{z e r o}(\mathbf{b} \neq \mathbf{0})$ correctly, introduce $\boldsymbol{a}$ as the numerator and $\boldsymbol{b}$ as the denominator, and explain fractions $\frac{\boldsymbol{a}}{\boldsymbol{b}}$ which is the magnitude of the whole. 
3.3. Idioms; The arrangement of idioms in mathematical material must be able to communicate mathematical concepts and terms so that they can be easily understood. [17] argues that comics are not just an art application, but comics are an art of communication. In this idoms principle, the delivery of the concept of fraction content $\left(\frac{\boldsymbol{a}}{\boldsymbol{b}}\right)$, uses eight aspects of the forms principle with the addition of several indicators on the visual aspect and selecting the appropriate color. In this case, it is necessary to present indicators: 1) character / character, 2) property, 3) background, 4) word balloons, and 5) sound effects to convey. These five indicators are more able to convey the mathematical material in question (the concept of fraction numbers $\frac{\boldsymbol{a}}{\boldsymbol{b}}$ )to consumers / readers.

3.4. Structure; Structure is the translation of mathematical material in a continuous story line. The structure of a simple story starting from the beginning/ introduction (introduction), beginning of the problem (conflict 1), conflict 2, climax, or it can change the order as needed and ends with problem solving (anti-climax). The principle of structure in motion comics is already relevant to the characteristics of mathematics in the form of structured and systematic science, so it remains only to store mathematical material in a structured manner on this structure principle [18].

3.5. Surface; The setting of place, time, character, culture can be developed into the background of the story that packs math material. This is related to five indicators: 1) character / character, 2) property, 3) background, 4) word balloons, and 5) sound effects to convey, which are used. This needs determination and development so that it has educational value. Especially mathematics material about the concept of fractions $\frac{\boldsymbol{a}}{\boldsymbol{b}}$ is to divide into several equal parts (concurrent).

3.6. Craft; Comic creation in developing mathematical material, where mathematics is designed in various contexts of stories, phenomena or events. In the context of fractions $\frac{a}{b}$, the story used can be a story that can accommodate the size of the part of the whole, or the magnitude of the part of an object, or the magnitude of the part of the whole.

\section{Conclusion}

Based on the results of a study conducted by the researcher regarding mathematical interpretation through motion comics, basically the principles of comic development provide an overview of the development of educational comics which are useful as learning media in schools. By paying attention to each principle of comic development, the process of interpreting mathematical material which is packaged in a visualized story becomes more attractive to students which of course provides additional alternative innovations in mathematics learning in schools.

\section{References}

[1] Purnama, S. Digital Care for Alpha Generation Children. Proceedings on Islamic Early Childhood Education. 2018; 1(1):493-502.

[2] Riansi, ES, \&Saputra, DY. Android-Based Interactive Multimedia as the Implementation of the 4.0 Industrial Revolution in Indonesian Language Learning in High Schools. In Check Language International Seminar; 2019.

[3] Husain, C. Utilization of information and communication technology in learning at SMA MuhammadiyahTarakan. Journal of Education Policy and Development. 2014; 2(2).

[4] Banggur, MDV. Blended Learning: Learning Solutions in the Industrial Revolution Era 4.0. LontoLeok Journal of Early Childhood Education. 2020; 3 (1):22-29. 
[5] Susanto, AMP. Learning and Learning Theory in Elementary Schools. Jakarta. KencanaPrenada Media Group; 2016.

[6] Zidniyati, Z. Strengthening Character Education in Elementary Schools in the Era of the Industrial Revolution 4.0. Tarbiyatuna: Islamic Education Studies. 2019; 3(1):41-58.

[7] Rohani, A. Educational Instructional Media. Jakarta. RinekaCipta; 1997.

[8] Hermawan, et al. Elementary School Learning Media. Bandung. UPI PRESS; 2007.

[9] Smith, C. Motion comics: The Emergence of a gybrid medium. Writing Visual Culture. Catebury Christ University; 2015.

[10] McCloud, S. Understanding Comics: The invisible art. New York. HarperCollins Books; 1993.

[11] Moleong, LJ. Revised Edisis Qualitative Research Methodology. Bandung. Rosda; 2008.

[12] Sugiyono. Educational Research Methods: (Quantitative, Qualitative, and R \& D Approaches). Bandung. Alfabeta; 2009.

[13] Borg, WR, \& Gall, MG. Educational Research: An Introduction (5th ed.). New York. Longman;1989.

[14] Creswell, JW. Educational Research. USA. Pearson Education; 2008.

[15] Eisner, WM. Graphic Storytelling and Visual Narrative: Second Edition. New York. WW Northon\& Company;2008.

[16] McCloud, S. Making Comics, Storytelling Secrets of Comics, Manga, and Graphic Novels: Creating Comics, Storytelling Secrets in Comics, Manga, and Graphic Novels. Alpha Febrianto translation. Jakarta. GramediaPustakaUtama; 2008.

[17] Koendoro, D. Come on, make a comic. Bandung. Mizan; 2007.

[18] Ajidarma, SG. Flag of Skulls: Culture in Conversation. Jakarta. Popular Gramedia Libraries; 2011 